\title{
CRUDE GLYCEROL UTILISATION IN MONOLAURIN PRODUCTION USING IMMOBILISED Rhizomucor miehei LIPASE: OPTIMISATION AND THERMODYNAMICS STUDY
}

NUR ARTIKAH MUHAMMAD SHAHRIN*; PEI WEN CHIN* and NOOR AZIAH SERRI

\begin{abstract}
The significant growth of biodiesel industry causes an excessive production of crude glycerol in Malaysia's market, especially being as one of the global biggest producers and exporters of palm oil. The ability of crude glycerol being reused as a substrate to produce monolaurin has been the main focus while catalysing the production efficiency using Lipozyme RM IM, a commercial immobilised Rhizomucor miehei lipase in a solvent-free system. Optimal reaction conditions obtained were 8:1 molar ratio of crude glycerol to lauric acid, temperature $47^{\circ} \mathrm{C}$, and lipase loading $1 \mathrm{wt} \%$ of lauric acid. Over $82 \%$ lauric acid conversion with 56 mol\% monolaurin yields was achieved within $8 \mathrm{hr}$. Using Arrhenius equation and transition-state theory, thermodynamic studies on monolaurin synthesis under the optimum conditions were performed. Energy of activation $\left(E_{a}\right)$ and energy of deactivation $\left(E_{d}\right)$ were found to be $89.5 \mathrm{~kJ} \mathrm{~mol}^{-1}$ and $110.7 \mathrm{~kJ} \mathrm{~mol}^{-1}$, respectively, suggesting that higher energy was required for enzyme irreversible denaturation to occur. Values of enthalpy $\left(86.90 \leq \Delta H \leq 86.84 \mathrm{~kJ} \mathrm{~mol}^{-1}\right)$, entropy $\left(0.29 \leq \Delta S \leq 0.28 \mathrm{~kJ} \mathrm{~mol} \mathrm{~K}^{-1}\right)$, and Gibbs free energy $(-2.53 \leq \Delta G \leq$ $\left.-5.22 \mathrm{~kJ} \mathrm{~mol}^{-1}\right)$ of the esterification were also determined.
\end{abstract}

Keywords: crude glycerol, monoglycerides, enzymatic reaction, lipase, thermodynamics.

Date received: 5 February 2019; Sent for revision: 18 February 2019; Received in final form: 13 May 2019; Accepted: 24 October 2019.

\section{INTRODUCTION}

Due to the rising concerns of global warming and energy deprivation, biodiesel as a renewable alternative fuel has been introduced and intensively produced in the last few decades. As a result, the main by-product from biodiesel synthesis, glycerol, has been massively produced. However, due to the costs associated with processing, capital, and

\footnotetext{
Bioprocess Technology, School of Industrial Technology, Universiti Sains Malaysia, 11800 Minden,

Pulau Pinang, Malaysia.

E-mail: aziah_serri@usm.my
}

transportation, thus, purification practice for the crude glycerol would not be a profitable option for biodiesel producers. If crude glycerol can be utilised as a building block for higher value-added compounds such as monoglycerides, the economic viability of the biodiesel production might be improved. Monoglycerides or monoacylglycerols (MAG) are widely used as synthetic surfactant or emulsifier in pharmaceutical, cosmetic, food, detergent, and plasticiser formulations. They represent about $70 \%$ of the synthetic emulsifiers used in food and pharmaceutical industries (Bruschweiler and Dieffenbacher, 1991; FerreiraDias et al., 2001; Chen and Terentjev, 2018). 
Besides the bulk applications as emulsifiers, monolaurin also known as glycerol monolaurate, a special type of MAG formed from lauric acid and glycerol, has been widely reported of having antimicrobial activities. For instance, this monoester was able to cause leakage of cell membrane of Staphylococcus aureus, a type of Gram-positive bacteria (Tangwatcharin and Khopaibool, 2012; Zhang et al., 2009). Besides, monolaurin also shows certain extent of virucidal effects towards measles, HIV, Herpes simplex-1, visna virus, vesicular stomatitis and cytomegalovirus (Lieberman et al., 2006).

At the industrial scale, MAG are manufactured by chemical glycerolysis of fats and oils at high temperature $\left(200^{\circ} \mathrm{C}-250^{\circ} \mathrm{C}\right)$, using inorganic catalysts under a nitrogen gas atmosphere (Gupta, 1996; Satriana et al., 2016; Hermida et al., 2017). However, this method creates many drawbacks. It consumes a lot of energy, generates dark coloured by-products and gives a low yield (30\%$50 \%$ ). Therefore, an additional distillation step is often required to obtain high purity MAG. To overcome these problems, enzymatic productions of MAG employing lipase have been developed due to milder conditions required. Several lipasecatalysed esterification approaches have been employed to produce MAG in organic medium (Cetina et al., 2011; Dom et al., 2014; Kapoor and Gupta, 2012; Zeng et al., 2010), in solventfree systems (Freitas et al., 2010; Ghamgui et al., 2006), or using microemulsion as reaction media (Itabaiana Jr et al., 2013). Solvent-free systems are more attractive because they avoid toxicity issues of the solvent and reduce purification steps, therefore lowering the cost of end products. Furthermore, MAG have potential use in food products, a solvent-free system is preferable.

The enzymatic glycerolysis and esterification of pure glycerol have been widely studied but there is an absence of information available on the enzymatic synthesis of MAG using biodiesel-derived crude glycerol. On top of that, thermodynamic studies concerning esterification of crude glycerol catalysed by lipase in a solvent-free system has not been disclosed in any published literature yet. In this work, biodiesel-derived crude glycerol was utilised for the synthesis of monolaurin catalysed by lipase from Rhizomucor miehei (Lipozyme RM IM). The esterification reaction was performed without any solvent or surfactant. In addition, crude glycerol was characterised and used without any further treatment. To study the thermostability of the immobilised enzyme in esterification reaction, optimal conditions of monolaurin yield was first being determined. Then, the thermodynamic aspect of lipase-catalysed synthesis of monolaurin was explored.

\section{MATERIALS AND METHODS}

\section{Materials}

Crude glycerol was kindly provided by a local biodiesel production plant, Lereno Sdn Bhd located in Perak, Malaysia and used for this work without prior purification. Lipozyme ${ }^{\circledR}$ RM IM (Rhizomucor miehei lipase immobilised on macroporous anionexchange resin) was purchased from Sigma-Aldrich Monolaurin, dilaurin, trilaurin, $\mathrm{n}$-Tetradecane and $\mathrm{N}, \mathrm{O}$-Bis(trimethylsilyl)acetamide were obtained from Sigma-Aldrich. Chloroform was purchased from Fisher Scientific. All the chemicals used are of analytical grade.

\section{Crude Glycerol Characterisation}

Sample of crude glycerol was sent to SGS laboratory in Selangor, Malaysia for characterisation. Determination of glycerol content was in accordance with British Standard (BS 5711-3:1979). Gravimetric analysis was performed to determine the amount of insoluble impurities. Determination of fatty acids content was based on American Oil and Chemical Society (AOCS) Official Method.

\section{Esterification of Lauric Acid with Crude Glycerol}

The esterification reactions were performed in $50 \mathrm{ml}$ screw-capped flasks. Crude glycerol and lauric acid were prepared into the flasks according to their molar ratio (2:1 to 10:1). Lipozyme RM IM of various loading ( 0.2 to $1.2 \mathrm{wt} \%$ ) was added to the reaction mixture. The reaction mixture was then incubated at the desired temperature $\left(40^{\circ} \mathrm{C}\right.$ to $\left.60^{\circ} \mathrm{C}\right)$ for $8 \mathrm{hr}$ with shaking at $200 \mathrm{rpm}$, using Ecotron shaker from INFORS HT.

\section{Sample Derivatisation for Gas Chromatography (GC) Analysis}

The reaction mixture obtained from esterification reactions were centrifuged at 3500 rpm for $10 \mathrm{~min}$ to separate into oil, glycerol, and enzyme layers. Derivatisation was achieved according to Watts and Dills (1969) with slight modifications. Fifty $\mu \mathrm{l}$ of sample was withdrawn from the resulting oil layer and diluted with 1 $\mathrm{ml}$ chloroform. Then, $0.1 \mathrm{ml}$ of internal standard (n-Tetradecane) was added followed by $0.2 \mathrm{ml}$ of TMS reagent [ $\mathrm{N}, \mathrm{O}$-Bis(trimethylsilyl)acetamide]. The resulting mixture was incubated at $70^{\circ} \mathrm{C}$ for $30 \mathrm{~min}$. Samples were analysed using GC with flame ionisation detector. SGE BPX5 (5\%-Phenyl Polysilphenylene Siloxane) non-polar capillary column $(30 \mathrm{~m} \times 0.25 \mathrm{~mm}$ i.d. $\times 0.25 \mu \mathrm{m}$ film thickness) was used. 
GC Analysis of Glycerides and Fatty Acid Conversion

Temperature program was set up as described previously by Bruschweiler and Dieffenbacber (1991). Fatty acid conversion was calculated based on the amount of lauric acid converted into products, as given in Equation (1).

Fatty acid conversion $(\%)=\left(\frac{A-B}{A}\right) \times 100 \% \quad$ Equation (1)

where, $A$ and $B$ are the peak areas for lauric acidTMS before and after esterification, respectively.

Monolaurin and dilaurin contents were expressed as the sum of weight of their regioisomers. The mol \% of each component was calculated as shown in Equation (2), Equation (3), and Equation (4).

$$
\text { Monolaurin }(\mathrm{mol} \%)=\frac{\text { Monolaurin }}{\text { Monolaurin+Dilaurin+ }} \times 100 \%
$$

Equation (2)

$$
\operatorname{Dilaurin}(\text { mol } \%)=\frac{\text { Dilaurin }}{\text { Monolaurin+Dilaurin+ }} \times 100 \%
$$

Equation (3)

$$
\operatorname{Trilaurin}(\text { mol } \%)=\frac{\text { Trilaurin }}{\begin{array}{l}
\text { Monolaurin }+ \text { Dilaurin }+ \\
\text { Trilaurin }+ \text { Lauric Acid }
\end{array}} \times 100 \%
$$

Equation (4)

\section{Optimisation of Monolaurin Synthesis Using RSM}

A $2^{\mathrm{k}}$ central composite design (CCD) of three parameters (substrate molar ratio, temperature, enzyme loading) was employed to obtain the optimal conditions for the esterification reactions. The randomised experiment was tabulated, and the responses were analysed by statistical software Design Expert ${ }^{\circledR}$ Version 7.0.0 (Stat-Ease, Inc., Minneapolis). Experimental data obtained were fitted into a second-order polynomial equation [Equation (5)] for generating response surface, which was used for predicting the optimum esterification point $(Y)$ :

$$
Y=\beta_{0}+\Sigma \beta_{i} X_{i}+\Sigma \beta_{i j} X_{i} X_{j}+\Sigma \beta_{i i} X_{i}^{2}+\varepsilon \quad \text { Equation (5) }
$$

where, $Y$ is the predicted response variable; $\beta_{0}$ is the constant coefficient; $\beta_{i}, \beta_{i i} \beta_{i j}$ are the coefficients for the linear, quadratic, and for the interaction effects, respectively; $X_{i}$ and $X_{j}$ are the coded level of variables $x_{i}$ and $x_{j}$ respectively and $\varepsilon$ is the error of the model (residual term).

\section{Thermodynamics Studies of Lipozyme RM IM on Monolaurin Synthesis}

The optimal conditions (substrate molar ratio and lipase loading) obtained from the optimisation part were further analysed for thermodynamic properties of monolaurin synthesis represented by the changes in enthalpy $(\Delta H)$, Gibbs free energy $(\Delta G)$ and entropy $(\Delta S)$. The thermodynamic studies consisted of investigating the effect of temperatures from $40^{\circ} \mathrm{C}$ to $60^{\circ} \mathrm{C}$ in accelerating or decelerating monolaurin production rate. Aliquots were withdrawn at periodic intervals to determine the initial reaction rate, $v_{0}$.

A plot of $\ln k$ versus $1 / \mathrm{T}$ was used to determine the activation energy $E_{a}$ as described by Arrhenius equation:

$$
\text { In } k=\left(-\frac{E_{a}}{R T}\right)+\operatorname{In} A \quad \text { Equation (6) }
$$

where, $\ln k$ is the reaction rate constant, $R$ is the universal gas constant $\left(8.314 \mathrm{~J} \mathrm{~mol}^{-1} \mathrm{~K}^{-1}\right), T$ is the absolute temperature $(\mathrm{K})$ and $A$ is the preexponential factor. The $E_{a}$ can be determined from the slope of the graph as described earlier (Khor et al., 2010; $\mathrm{Yu}$ and Li, 2006). Gibbs free energy $\Delta G$ enthalpy, energy $\Delta H$ and entropy energy $\Delta S$ of the enzymatic reaction can be calculated according to the following equations (Jin et al., 2015; Pogaku et al., 2012):

$$
\Delta H=E_{a}-R T
$$

Equation (7)

$$
\begin{aligned}
& \Delta G=\Delta H-R T \\
& \text { In } k=\frac{\Delta H}{R T}-\frac{\Delta S}{R}
\end{aligned}
$$$$
\text { Equation (8) }
$$

Equation (9)

\section{Irreversible Denaturation and Thermal Stability of Lipase}

Thermal stability of Lipozyme RM IM was studied by incubating the enzyme in lauric acid suspension without glycerol at $50^{\circ} \mathrm{C}, 55^{\circ} \mathrm{C}$ and $60^{\circ} \mathrm{C}$ for variable periods of one to four days. In order to determine the lipase residual activity, esterification was re-performed as described above.

$$
\Psi=\frac{v}{v_{\mathrm{o}}} \quad \text { Equation (10) }
$$

From Equation (10), $\Psi$ is the activity coefficient, $v$ is the initial reaction rates of unheated lipase and $v_{0}$ is the initial reaction rates for lipase that has undergone thermal treatment.

The thermodynamic parameters of the irreversible denaturation of the enzyme can be then be estimated according to Eyring equation:

$$
k_{d}=T \frac{k_{B}}{h} e \frac{\Delta S}{R} e-\Delta H / R T \quad \text { Equation (11) }
$$


where $\mathrm{k}_{\mathrm{d}^{\prime}} \mathrm{T}, \mathrm{k}_{\mathrm{B}^{\prime}}, h$ and $\mathrm{R}$ are deactivation constant, absolute temperature, Boltzmann constant, Planck's constant and gas constant, respectively (Khor et al., 2010). Determination of $\mathrm{k}_{\mathrm{d}}$ at each temperature will also lead to enzyme's half-life at particular temperature (Marangoni, 2003).

$$
t_{1 / 2}=\frac{0.693}{k_{d}} \quad \text { Equation (12) }
$$

\section{RESULTS AND DISCUSSION}

\section{Components in Crude Glycerol}

The characteristic of crude glycerol used is shown in Table 1. The purity of crude glycerol was $88.35 \%$ with $10.65 \%$ moisture content plus other insoluble impurities around $0.10 \%$. The result clearly displayed that less than $1 \%$ of the remaining content were a mixture of different types of fatty acid. As expected, C16:0 (palmitic acid) dominated the total amount of fatty acids content followed by C18:1 (oleic acid) because the crude glycerol obtained was derived from biodiesel reaction using palm oil. Therefore, no pre-treatment was conducted on the substrate due to high glycerol content.

\section{Optimisation for Monolaurin Production}

Analysis of variance (ANOVA) using Fisher's F-tests was conducted as presented in Table 2. The ANOVA revealed that the model was capable to represent the actual relationship between monolaurin yield and the significant factors. The F-value of the model (154.54) with a Prob $(F)<0.0001$ indicated that the model was significant at $95 \%$ confidence level. The lack of fit F (3.46) implies that it is not significant
TABLE 1. CRUDE GYLCEROL COMPOSITION

\begin{tabular}{|c|c|}
\hline Content & Composition \\
\hline Glycerol content $(\%)$ & 88.35 \\
\hline Moisture (\%) & 10.65 \\
\hline Insoluble impurities $(\%)$ & 0.074 \\
\hline \multicolumn{2}{|l|}{ Fatty acids composition (\%) } \\
\hline$-\mathrm{C} 6: 0$ & 7.8 \\
\hline$-C 8: 0$ & 9.0 \\
\hline$-\mathrm{C} 10: 0$ & $<0.1$ \\
\hline$-\mathrm{C} 12: 0$ & $<0.1$ \\
\hline$-\mathrm{C} 14: 0$ & $<0.1$ \\
\hline$-\mathrm{C} 16: 0$ & 50.7 \\
\hline$-\mathrm{C} 16: 1$ & $<0.1$ \\
\hline$-\mathrm{C} 18: 0$ & $<0.1$ \\
\hline$-\mathrm{C} 18: 1$ & 32.5 \\
\hline$-\mathrm{C} 18: 2$ & $<0.1$ \\
\hline$-\mathrm{C} 20: 0$ & $<0.1$ \\
\hline$-\mathrm{C} 18: 3$ & $<0.1$ \\
\hline
\end{tabular}

relative to pure error. Also, the precision of the model can be checked by coefficient of determination $\left(R^{2}\right.$ value). The $R^{2}$ of 0.9929 and adjusted $R^{2}$ value of 0.9864 also showed that the model has high goodness of fit. Within the range studied, all individual factors [substrate molar ratio (A), temperature (B), and lipase loading $(C)$ ] showed significant effect towards monolaurin yield with Prob (F) value of less than 0.05 . On the other hand, only one interaction effect between the factors [substrate molar ratio and temperature $(\mathrm{AB})]$ was found to be significant during esterification of monolaurin.

Figure 1 shows the effect of glycerol to lauric acid molar ratio, temperature and their mutual interaction (P-value $=0.0136)$ on the yield of monolaurin at a fixed amount of enzyme loading (1 wt \% lauric acid). At the lowest reaction temperature $\left(40^{\circ} \mathrm{C}\right)$ with the lowest substrate molar ratio $(3: 1)$,
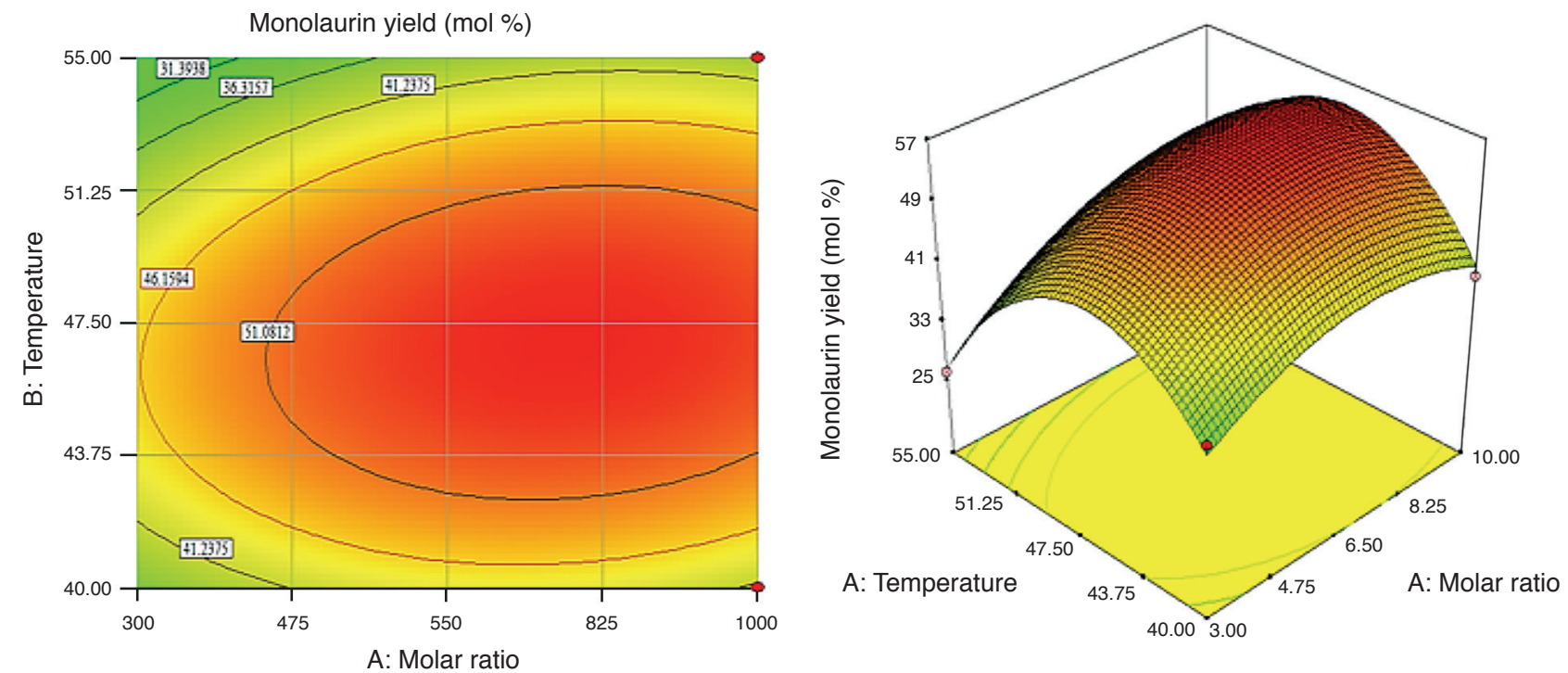

Figure 1. (a) Contour plot (b) response surface plot of monolaurin yield as a function of temperature and substrate molar ratio at fixed lipase loading of 1 wt \% lauric acid. 
the monolaurin yield was only $37.54 \mathrm{~mol} \%$. Further increase of the temperature to $47.5^{\circ} \mathrm{C}$ and molar ratio to $8: 1$ could bring a maximal yield of over $50 \mathrm{~mol}$ $\%$. This indicated that temperature and molar ratio greatly affected the monolaurin yield (response), which agreed with the previous outcome of ANOVA test (Table 2). When the temperature increases, collisions between enzyme and substrate molecules are speeded up and causes the increase of reaction rate. However, the yield of monolaurin decreased with an increase in temperature. This negative effect might be associated with the loss of enzyme activity due to denaturation. It has been reported in numerous studies that the reaction temperature of $45^{\circ} \mathrm{C}$ to $55^{\circ} \mathrm{C}$ is optimal for Lipozyme RM IM performance on esterification reactions (Bernardes et al., 2007; Manurung et al., 2015).

Response surface plots display function of two factors at one time while keeping other factors at a constant level are useful in understanding both the main and interaction effects of these factors. The yield response for different combination of parameters levels can be easily predicted from the relevant response surface plots. Monolaurin yield (Figure $1 b$ ) increased with increasing molar ratio of glycerol to lauric acid (3:1 to 8:1). It has been proven that excess glycerol favoured the yield of glyceride esters (Freitas et al., 2007; Pereira et al., 2004; Zhao et al., 2011). This is most likely due to the excess glycerol which can push the reaction equilibrium to the right side, favouring esterification rather than hydrolysis. However, further increase in molar ratio to $10: 1$ led to a slight reduction in the yield. As the glycerol content increases, the solution viscosity also increases, causing mass transfer limitation. Also, it has been confirmed that alcoholic groups are terminal inhibitors of lipase (Mhetras et al., 2010).
The optimal conditions for lipase-catalysed monolaurin synthesis, using Lipozyme RM IM were determined by the response desirability profile. The optimised conditions with desirability of 0.977 were: 8:1 glycerol:lauric acid molar ratio, $47^{\circ} \mathrm{C}$ and 1 wt $\%$ lipase loading. Experiments were conducted under optimum conditions with three replications and the results were tested using single sample t-test. Under these optimum conditions, the monolaurin yield was predicted to be $56 \mathrm{~mol}$ $\%$, with a p-value of 0.116 , bigger than $0.05(95 \%$ confidence level) showed that the experimental data had no significant different with the predicted data by Design Expert software. This indicates that the model was validated, and the optimisation was considered successful.

\section{Thermodynamics Studies on Lipozyme RM IM}

The initial reaction rate, $v_{0}$ of monolaurin yield under various temperature of $40^{\circ} \mathrm{C}$ to $60^{\circ} \mathrm{C}$ is presented in Figure 2. The figure clearly displays two different trends according to the monolaurin produced. The initial reaction rate progressively increased with temperature up to $47^{\circ} \mathrm{C}$. Beyond this threshold value, monolaurin production rate decreased with increasing temperature, therefore was considered as a non-productive region. Previous studies have found that, the catalysing activity of Lipozyme RM IM was usually performed at $45^{\circ} \mathrm{C}$ to $50^{\circ} \mathrm{C}$ regardless of acyl donators and acyl acceptors (Bernardes et al., 2007; Ungcharoenwiwat et al., 2016; Yadav et al., 2014). The positive relationship between monolaurin production rate and temperature was in accordance with the Arrhenius model. Arrhenius plot was used to estimate the activation energy and reversible unfolding energy (Figure 3).

TABLE 2. ANALYSIS OF VARIANCE (ANOVA) TABLE OF QUADRATIC MODEL

\begin{tabular}{|c|c|c|c|c|c|}
\hline Source & Sum of squares & $\begin{array}{c}\text { Degrees of } \\
\text { freedom }\end{array}$ & Mean square & F value & $\begin{array}{c}\text { P-value }^{*} \\
\text { Prob }>\text { F }\end{array}$ \\
\hline Model & 4941.76 & 9 & 549.08 & 154.54 & $<0.0001$ \\
\hline $\mathrm{A}$ & 194.19 & 1 & 194.19 & 54.65 & $<0.0001$ \\
\hline B & 94.86 & 1 & 94.86 & 26.70 & 0.0004 \\
\hline $\mathrm{C}$ & 1463.03 & 1 & 1463.03 & 411.76 & $<0.0001$ \\
\hline $\mathrm{AB}$ & 31.76 & 1 & 31.76 & 8.94 & 0.0136 \\
\hline $\mathrm{AC}$ & 1.77 & 1 & 1.77 & 0.50 & $0.4968^{a}$ \\
\hline $\mathrm{BC}$ & 0.50 & 1 & 0.50 & 0.14 & $0.7154^{\mathrm{a}}$ \\
\hline $\mathrm{A}^{2}$ & 403.09 & 1 & 403.09 & 113.45 & $<0.0001$ \\
\hline $\mathrm{B}^{2}$ & 2904.44 & 1 & 2904.44 & 817.43 & $<0.0001$ \\
\hline $\mathrm{C}^{2}$ & 151.43 & 1 & 151.43 & 42.62 & $<0.0001$ \\
\hline Residual & 35.53 & 10 & 3.55 & - & - \\
\hline Lack of Fit & 27.56 & 5 & 5.51 & 3.46 & $0.0998^{a}$ \\
\hline Pure Error & 7.97 & 5 & 1.59 & - & - \\
\hline Cor Total & 4977.29 & 19 & - & - & - \\
\hline
\end{tabular}

Note: *A - glycerol:lauric acid molar ratio; B - temperature $\left({ }^{\circ} \mathrm{C}\right)$; C - lipase loading (wt \% of lauric acid).

*Statistically significant at $95 \%$ confidence level.

${ }^{\text {a }}$ Not significant. 


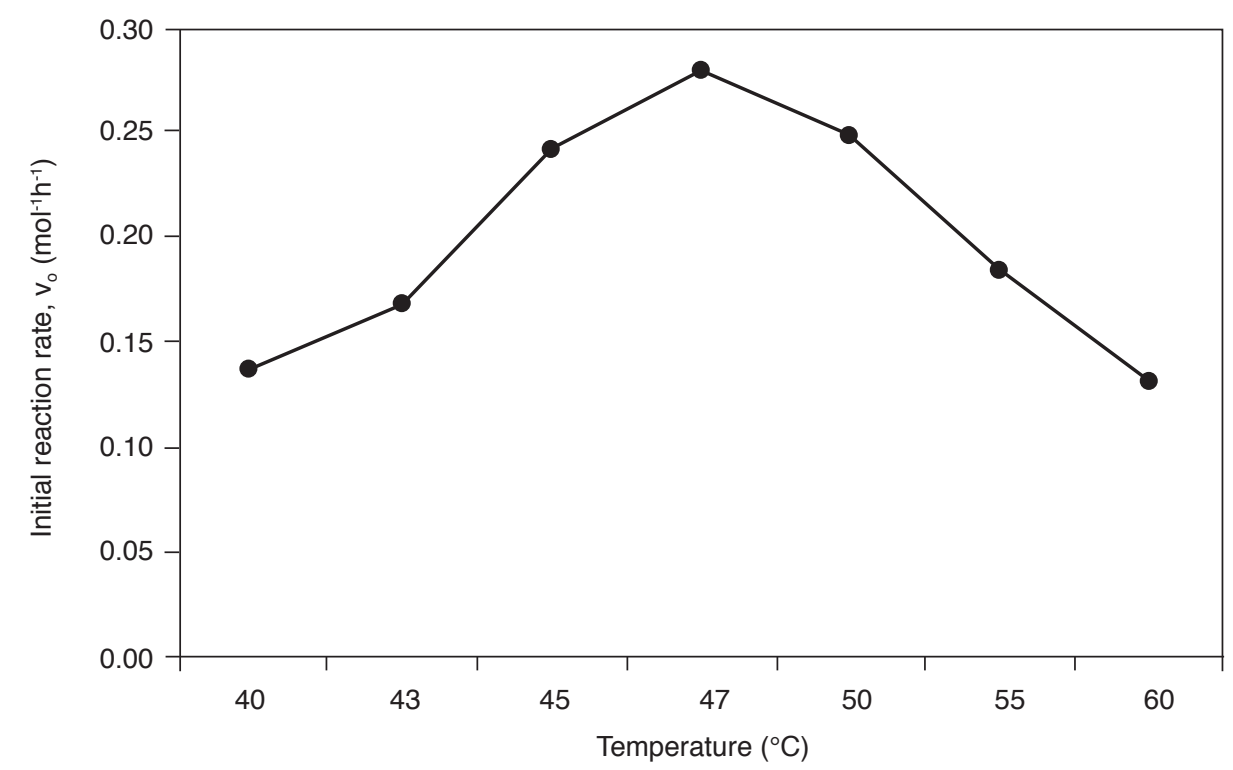

Figure 2. Initial reaction rate of monolaurin yield under different operating temperatures (reaction conditions: 8:1 glycerol/lauric acid molar ratio; 1 wt \% lipase loading; 200 rpm)

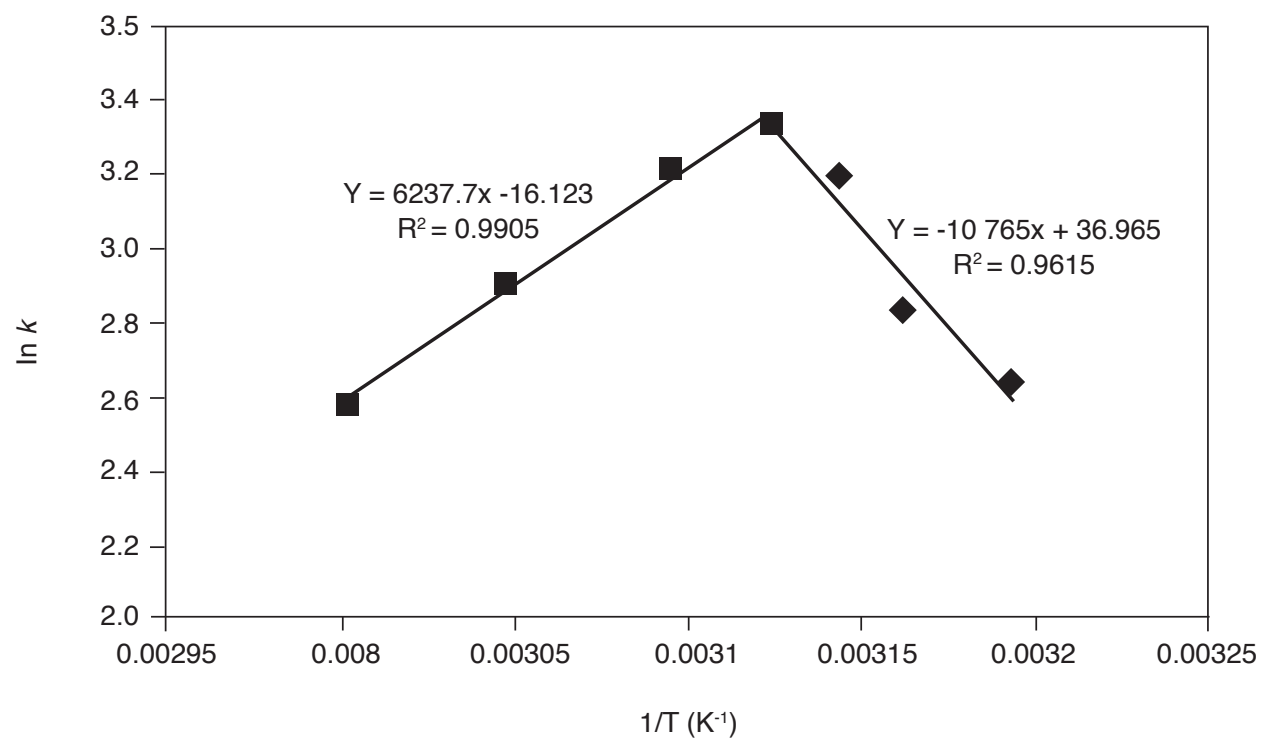

Figure 3. Arrhenius plots for the estimation of activation energy and reversible denaturation energy $\left(40^{\circ} \mathrm{C}-60^{\circ} \mathrm{C}\right)$.

The Arrhenius plot associates the natural logarithm of the reaction rate constant $(\ln k)$ with the inverse of temperature $(1 / \mathrm{T})$. Figure 3 presents the activation energy which was calculated from the slope below the threshold temperature [intersect value of $\ln k\left(47^{\circ} \mathrm{C}\right)$ ] and was found to be $89.5 \mathrm{~kJ} \mathrm{~mol}^{-1}\left(\mathrm{R}^{2}=0.9651\right)$, whereas the reversible denaturation energy was estimated from the slope above the threshold and the value was found to be $51.86 \mathrm{~kJ} \mathrm{~mol}^{-1}\left(\mathrm{R}^{2}=0.9651\right)(\mathrm{Yu}$ and $\mathrm{Li}, 2006)$. Most of the reactions have $E_{a}$ values ranging from $40 \mathrm{~kJ}$ $\mathrm{mol}^{-1}$ to $400 \mathrm{~kJ} \mathrm{~mol}^{-1}$ (Qu et al., 2013). For this work, the activation energy was higher than the reversible denaturation energy, suggesting that higher energy is required for esterification reaction to go forward than unfolding of the enzyme. However, contrary to this study, previous studies reported for Lipozyme TL IM (Activation energy $=22.15 \mathrm{~kJ} \mathrm{~mol}^{-1}$; Deactivation energy $\left.=45.18 \mathrm{~kJ} \mathrm{~mol}^{-1}\right)$, tannase from Apergillus niger (Activation energy $=23.29 \mathrm{~kJ} \mathrm{~mol}^{-1}$; Deactivation energy $=62.85 \mathrm{~kJ} \mathrm{~mol}^{-1}$ ) and Candida antarctica lipase B (Activation energy $=22.15 \mathrm{~kJ}$ $\mathrm{mol}^{-1}$; Deactivation energy $=\mathrm{kJ} \mathrm{mol}^{-1}$ ) have shown that these enzymes required higher energy to unfold their active sites than to activate it (Khor et al., 2010; $\mathrm{Yu}$ and $\mathrm{Li}, 2006)$. Hence, a probable reason is the high viscosity of the reaction mixture in a solventfree system required higher energy to bring nonactivation molecules into activation molecules. This is according to Kramers' theory, where viscosity of reaction mixture consequently would introduce friction against any proteins in the system and this 
eventually restricted the protein motion, inhibiting catalysis in motile enzymes. For this work, viscosity happened by increasing of crude glycerol concentration in the absence of solvent (Kumar et al., 2016; Uribe and Sampedro, 2003).

Determination of Thermodynamic Properties $\Delta H$, $\Delta S$ and $\Delta G$

The enthalpy of activation $(\Delta H)$, entropy of activation $(\Delta S)$ and Gibbs free energy of activation $(\Delta G)$ at each activation temperature were calculated according to Equations (7) - (9). Results are presented in Table 3. The endothermic nature of the esterification reaction was confirmed by the positive value of enthalpy $(\Delta H)$. Heat needs to be input for enzyme catalysis to occur. Furthermore, these values indicate that lower enthalpy of activation was needed as the temperature increased. This is probably due to high temperature which promotes collision between the reactant molecules. Entropy $(\Delta S)$ is the measure of disorder in a system. Positive entropy indicates an increase of disorder in the system. The value did not show any significant changes suggesting that lipase configuration remains the same despite changing in temperature (Bhatti and Amin, 2013). The microenvironment around the enzyme could

TABLE 3. THERMODYNAMIC PARAMETERS OF LAURIC ACID AND CRUDE GLYCEROL ESTERIFICATION, ESTIMATED BY THE ARRHENIUS MODEL UNDER DIFFERENT ACTIVATION TEMPERATURE

\begin{tabular}{|c|c|c|c|}
\hline Temperature (K) & $\Delta \mathrm{H}, \mathrm{kJ} \mathrm{mol}^{-1}$ & $\Delta S, \mathrm{~kJ} \mathrm{~mol}^{-1} \mathrm{~K}^{-1}$ & $\Delta \mathrm{G}, \mathrm{kJ} \mathrm{\textrm {mol } ^ { - 1 }}$ \\
\hline 313.15 & 86.90 & 0.29 & -5.22 \\
\hline 316.15 & 86.87 & 0.29 & -4.18 \\
\hline 318.15 & 86.86 & 0.28 & -3.78 \\
\hline 320.15 & 86.84 & 0.28 & -2.53 \\
\hline
\end{tabular}

significantly affect the entropy value ( $\mathrm{Yu}$ and $\mathrm{Li}$, 2006). The Gibbs free energy $(\Delta G)$ shows negative value, validating that the reaction will proceed spontaneously and is said to be exergonic. This thermodynamic study demonstrates a favourable condition towards monolaurin synthesis (Aledo et al., 2003; Berg et al., 2002).

\section{Irreversible Denaturation and Thermal Stability of Lipase}

To evaluate the irreversible denaturation rate of Lipozyme RM IM, the enzyme was treated with various thermal conditions and its residual activity was determined. The first order rate constant of lipase deactivation, $k_{d}$ at different temperature can be estimated from the slope by plotting $\ln \Psi$ versus time (days), where $\Psi$ is the activity coefficient as shown in Figure 4. The experimental results indicated that $k_{d}$ continuously increased from 0.073 to 0.246 day $^{-1}\left(0.0031\right.$ to $\left.0.0103 \mathrm{hr}^{-1}\right)$ when the temperature increased from $50^{\circ} \mathrm{C}$ to $60^{\circ} \mathrm{C}$. Enzyme stability decreased with increasing $k_{d}$ at a certain temperature (Khor et al., 2010). To validate Lipozyme RM IM stability, its half-life, $t_{1 / 2}$ was determined. Half-life of an enzyme is the time it takes for its activity to reduce to a half of the original activity. The calculated values for half-life of the lipase were 9.5 (228 hr), 5 (120 hr) and $3\left(72 \mathrm{hr}\right.$ ) days for $50^{\circ} \mathrm{C}, 55^{\circ} \mathrm{C}$, and $60^{\circ} \mathrm{C}$, respectively. Both $k_{d}$ and $t_{1 / 2}$ values showed that the lipase has moderate thermal stability over a period of time. Based on the denaturation constant, the energy of irreversible denaturation obtained from Arrhenius equation was $110.7 \mathrm{~kJ} \mathrm{~mol}^{-1}$, higher than that of the activation energy $\left(89.5 \mathrm{~kJ} \mathrm{~mol}^{-1}\right)$. This reveals that the enzyme activation can be attained at lower temperature, whilst higher temperature would hasten the denaturation rate of enzyme (Khor et al., 2010).

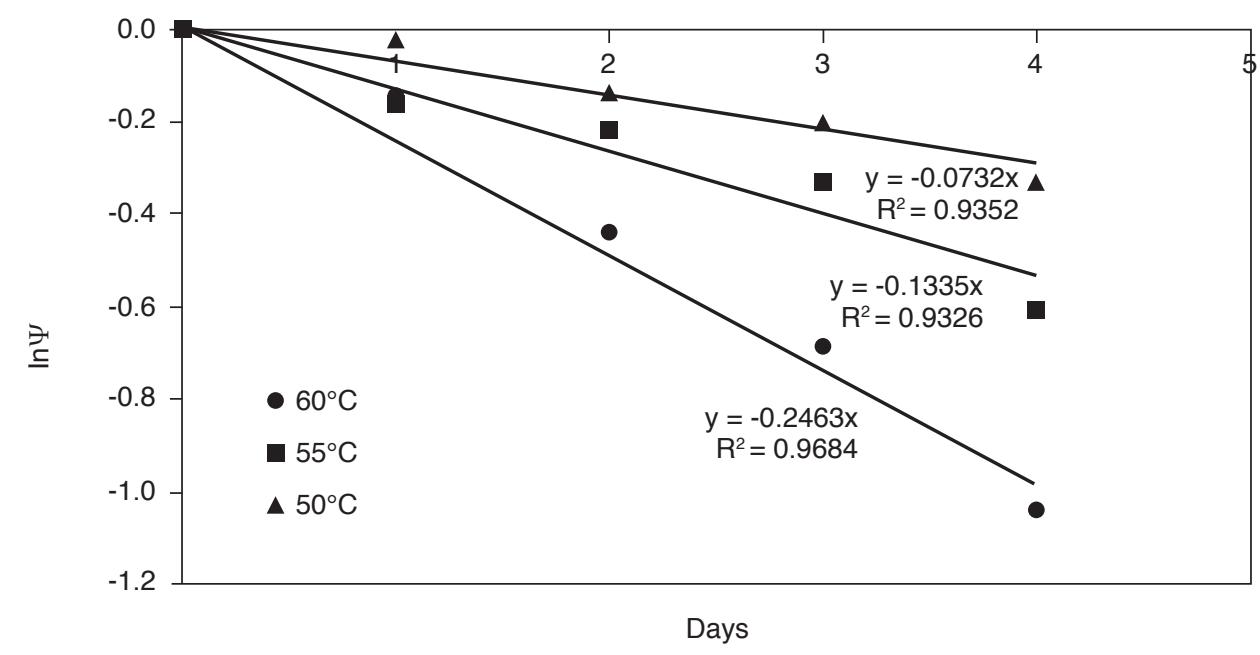

Figure 4. Initial reaction rate of monolaurin yield versus different heat treatment $\left(50{ }^{\circ} \mathrm{C}-60^{\circ} \mathrm{C}\right)$ for variables times $(1-4$ days). Reaction conditions: 8:1 glycerol/lauric acid molar ratio; 1 wt \% lipase loading; $200 \mathrm{rpm}$. 


\section{CONCLUSION}

The work has demonstrated feasibility of using crude glycerol as a substrate for monolaurin production in a solvent-free system using Lipozyme RM IM as catalyst. Response surface methodology was able to predict the optimum reaction which were $8: 1$ crude glycerol to lauric acid ratio, $47^{\circ} \mathrm{C}$ and $1 \%$ wt lipase loading. At optimum conditions, monolaurin yield was attained at $56 \mathrm{~mol} \%$. The thermodynamic studies obtained a negative Gibbs free energy, whereas both enthalpy and entropy gave positive values, indicating endothermic, spontaneous and irreversible nature of the reaction. The optimisation and thermodynamics data obtained could be useful for process improvement and industrial utilisation of crude glycerol for monoglycerides synthesis in the future.

\section{ACKNOWLEDGEMENT}

The authors acknowledge Lereno Sdn Bhd for providing the crude glycerol. This work was funded by the Ministry of Education, Malaysia (KPM), Transdisciplinary Research Grant Scheme (TRGS), (grant number 6762003).

\section{REFERENCES}

Aledo, J C; Lobo, C and Valle, A C (2003). Energy diagrams for enzyme catalyzed reactions: Concepts and misconcepts. Biochemistry and Molecular Biology Education, 31: 234-236.

Berg, J M; Tymoczko, J L and Stryer, L (2002). Section 8.2 , Free energy is a useful thermodynamic function for understanding enzymes. Biochemistry. $5^{\text {th }}$ edition. W H Freeman Publishers, New York. 1515 pp.

Bernardes, O L; Bevilaqua, J V; Leal, M C; Freire, D M and Langone, M A (2007). Biodiesel fuel production by the transesterification reaction of soybean oil using immobilized lipase. Appl. Biochem. and Biotechnol., 137: 105-114.

Bhatti, H N and Amin, F (2013). Kinetic and hydrolytic characterization of newly isolated alkaline lipase from Ganoderma lucidum using canola oil cake as substrate. J. Chemical Soc. Pakistan, 35: 585-592.

Bruschweiler, H and Dieffenbacher, A (1991). Determination of mono- and diglycerides by capillary gas chromatography: results of a collaborative study and the standardized method. Pure and Appl. Chem., 63: 1153-1162.
Cetina, D M; Giraldo, G I and Orrego, C E (2011). Application of response surface design to solvent, temperature and lipase selection for optimal monoglyceride production. J. Mol. Catal. B: Enzymatic, 72: 13-19.

Chen, C H and Terentjev, E M (2018). Chapter 5 Monoglycerides in oils. Edible Oleogels - Structure and Health Implication (Marangoni, A and Garti, N eds.). Academic Press and AOCS Press, Illinois. p. 103-131.

Dom, Z M; Chuan, L and Yusoff, R (2014). Production of medium chain acylglycerols by lipase esterification in packed bed reactor: Process optimization by response surface methodology. J. Engine Science and Technol., 9: 384-397.

Ferreira-Dias, S; Correia, A; Baptista, F and Fonseca, M D (2001). Contribution of response surface design to the development of glycerolysis systems catalyzed by commercial immobilized lipases. J. Mol. Catal. B: Enzymatic, 11: 699-711.

Freitas, L; Paula, A V; Santos, J C; Zanin, G M and Castro, H F (2010). Enzymatic synthesis of monoglycerides by esterification reaction using Penicillium camembertii lipase immobilized on epoxy $\mathrm{SiO}_{2}$-PVA composite. J. Mol. Catal. B: Enzymatic, 65: 87-90.

Freitas, L; Perez, V H; Santos, J C and Castro, H F (2007). Enzymatic synthesis of glyceride esters in solvent-free system: Influence of the molar ratio, lipase source and functional activating agent of the support. J. Brazilian Chemical Soc., 18: 1360-1366.

Ghamgui, H; Miled, N; Rebaï, A; Karra-Chaâbouni, $\mathrm{M}$ and Gargouri, Y (2006). Production of monoolein by immobilized Staphylococcus simulans lipase in a solvent-free system: Optimization by response surface methodology. Enzyme and Microbial Technol., 39: 717-723.

Gupta, M (1996). Manufacturing process for emulsifiers. Bailey's Industrial Oil and Fat Products (Hui, Y H ed.). $5^{\text {th }}$ Edition. John Wiley and Sons, Inc., New York. p. 569-601.

Hermida, L; Amani, H; Saeidi, S; Abdullah, A Z and Mohamed, A R (2017). Selective acid-functionalized mesoporous silica catalyst for conversion of glycerol to monoglycerides: state of the art and future prospects. Reviews in Chemical Engineering, 34: 239265.

Itabaiana Jr, I; Gonçalves, K; Cordeiro, Y; Zoumpanioti, M; Leal, I; Miranda, L; De Souza, R and Xenakis, A (2013). Kinetics and mechanism of 
lipase catalyzed monoacylglycerols synthesis. J. Mol. Catal. B: Enzymatic, 96: 34-39.

Jin, J; Ma, H; Wang, K; Yagoub, A G; Owusu, J; Qu, W; He, R; Zhou, C and Ye, X (2015). Effects of multifrequency power ultrasound on the enzymolysis and structural characteristics of corn gluten meal. Ultrasonics Sonochemistry, 24: 55-64.

Kapoor, M and Gupta, M N (2012). Obtaining monoglycerides by esterification of glycerol with palmitic acid using some high activity preparations of Candida antarctica lipase B. Proc. of the Biochem., 47: 503-508.

Khor, G K; Sim, J H; Kamaruddin, A H and Uzir, M $H$ (2010). Thermodynamics and inhibition studies of Lipozyme TL IM in biodiesel production via enzymatic transesterification. Bioresource Technol., 101: 6558-6561.

Kumar, A; Dhar, K, Kanwar, SS and Arora, PK(2016). Lipase catalysis in organic solvents: Advantages and applications. Biological Procedures Online, 18: 2(1).

Lieberman, S; Enig, M G and Preuss, H G (2006). A review of monolaurin and lauric acid: Natural virucidal and bactericidal agents. Alternative and Complementary Therapies, 12: 310-314.

Manurung, R; Hasibuan, R; Taslim, T; Rahayu, N S and Darusmy, A (2015). Enzymatic transesterification of dpo to produce biodiesel by using Lipozyme RM IM in ionic liquid system. Procedia-Social and Behavioral Sciences, 195: 2485-2491.

Marangoni, A G (2003). Chapter 12: Characterization of enzyme stability. Enzyme kinetics: AModern Approach. John Wiley and Sons, Inc., New York. p. 140-157.

Mhetras, N; Patil, S and Gokhale, D (2010). Lipase of Aspergillus niger NCIM 1207: A potential biocatalyst for synthesis of isoamyl acetate. Indian J. Microbiol., 50: 432-437.

Pereira, C C; Silva, M A and Langone, M A (2004). Enzymatic synthesis of monolaurin. Proc. of the $25^{\text {th }}$ Symposium on Biotechnology for Fuels and Chemicals. Breckenridge, CO: Springer. p. 433-445.

Pogaku, R; Raman, J K and Ravikumar, G (2012). Evaluation of activation energy and thermodynamic properties of enzyme-catalysed transesterification reactions. Adv. Chem. Eng. Sci., 2: 150-154.

Qu, W; Ma, H; Liu, B; He, R; Pan, Z and Abano, E E (2013). Enzymolysis reaction kinetics and thermodynamics of defatted wheat germ protein with ultrasonic pretreatment. Ultrasonics Sonochemistry, 20: 1408-1413.

Satriana; Arpi, N; Lubis, Y M; Adisalamun, Supardan, M D and Wan Mustapha, W A (2016). Diacylglycerol-enriched oil production using chemical glycerolysis. European J. Lipid Science and Technology, 118: 1880-1890.

Tangwatcharin, P and Khopaibool, P (2012). Activity of virgin coconut oil, lauric acid or monolaurin in combination with lactic acid against Staphylococcus aureus. Southeast Asian J. Trop. Med. and Pub. Health, 43: 969-985.

Ungcharoenwiwat, P; Canyuk, B and Aran, H-K (2016). Synthesis of jatropha oil based wax esters using an immobilized lipase from Burkholderia sp. EQ3 and Lipozyme RM IM. Proc. of the Biochem., 51: 392-398.

Uribe, S and Sampedro, J S (2003). Measuring solution viscosity and its effect on enzyme activity. Biological Procedures Online, 5: 108-115.

Watts, R and Dils, R (1969). Separation of mono- and diglycerides by gas-liquid chromatography. J. Lipid Research, 10: 33-40.

Yadav, A; Singh, R P; Upadhayay, S K and Butler, H (2014). Kinetic investigation of enzymatic synthesis of sucrose fatty acid esters from sucrose and nonedible rice bran fatty acid. Int. J. Science $\mathcal{E}$ Technol., 3: 384-390.

Yu, X W and Li, Y Q (2006). Kinetics and thermodynamics of synthesis of propyl gallate by mycelium-bound tannase from Aspergillus niger in organic solvent. J. Mol. Catal. B: Enzymatic, 40: 44-50.

Zeng, F K; Yang, B; Wang, Y H; Wang, W F; Ning, $\mathrm{Z} X$ and Li, L (2010). Enzymatic production of monoacylglycerols with camellia oil by the glycerolysis reaction. J. Amer. Oil Chem. Soc., 87: 531-537.

Zhang, H; Shen, Y; Weng, P; Zhao, G; Feng, F and Zheng, X (2009). Antimicrobial activity of a food-grade fully dilutable microemulsion against Escherichia coli and Staphylococcus aureus. Int. J. Food Microbiol., 135: 211-215.

Zhao, Y; Liu, J; Deng, L; Wang, F and Tan, T (2011). Optimization of Candida sp. 99-125 lipase catalyzed esterification for synthesis of monoglyceride and diglyceride in solvent-free system. J. Mol. Catal. B: Enzymatic, 72: 157-162. 